\title{
SURFACE ARTERY VOLUME PULSE WAVE MEASUREMENT - VERIFICATION OF A NEW METHOD
}

\author{
David Korpas ${ }^{\mathrm{a}}$, Jan Hálek ${ }^{\mathrm{a}}$, Ludmila Chlupováb
}

\author{
a Institute of Medical Biophysics, Faculty of Medicine, Palacky University, Olomouc \\ $b$ Department of Special Education, Pedagogical Faculty, Palacky University, Olomouc \\ korpasbz@tunw.upol.cz
}

Received: November 7, 2003; Accepted: November 29, 2003
Key words: Pulse wave / Forearm blood flow / Plethysmography / Arterial elasticity / Blood volume / Measurement techniques

The aim of this paper is to prove the possible reproducibility of measurement with a new developed device for artery elasticity monitoring and determining the standard of major pulse wave parameters. As a measurement sensor, a conic probe with thin convex membrane was used. This technique allows setting an arbitrary pressure to a measured surface artery. We measured pulse waves on the radial arteries of 108 individuals. We expected similar features in arterial wall elasticity. We concentrated primarily on the amount of subcutaneous fat. For the measured waves we evaluated five following pulse wave parameters: relative crest time, elasticity index, dicrotic wave attenuation, dicrotic wave time and interwave distance. There were no significant differences in measured pulse wave parameters among the tested groups of subjects.

\section{INTRODUCTION}

The human forearm is a well-established model for studying local vascular reactivity in humans ${ }^{1}$. Pulse wave is a complex physiological phenomenon, observable and measurable in the arterial system during blood circulation. During one heart systole, a certain blood volume is expelled. This propagates through the arteries due to the reciprocal transformation between kinetic energy of a segment of the expelled blood volume and the potential energy of a stretched segment of the resilient vascular wall. We can observe the changes in pressure, blood flow, velocity and profile throughout the whole pulse wave. It can be used for classification of the artery elasticity.

There are already several methods of noninvasive pulse wave measurement based on other principles ${ }^{2,3}$. The easiest one is using the tonometry cuff, connected to the pressure sensor. Next there is a clinically used Doppler ultrasound. The transparent and reflex photoplethysmography method is also used quite often. There are also methods based on direct measurement of volume changes using pressure transducers with inductive or capacity probes. Our method uses a differential pressure transmitter and therefore the sensitivity is much higher. It also allows setting an arbitrary pressure to the surface artery.

We measured the pulse wave on radial artery, but the method is sensitive enough also to be used for measurements on other arteries, like superficial temporal artery, posterior tibial artery or dorsalis pedis artery. The aim of the study was to prove the reproducibility of pulse wave measurement by the new developed device on the subjects with various body conditions.

\section{MATERIALS AND METHODS}

\section{Description of measurement technique}

The device for measuring and analyzing the pulse wave consists of (Fig. 1) a scanning membrane on a probe. Next there is liquid and air part for pressure transmission, a differential pressure transducer, a measuring card and a PC with software for analyzing and storage of pulse waveforms ${ }^{4}$. The method is based on generally known possibility of palpation. Using our method, the pulse wave changes the artery diameter and it is scanned directly by an adhesive, very thin membrane, which has a convex form because of an inside pressure of the liquid media. The volume changes convert back into pressure changes and transfer to the positive entry of a highly sensitive differential pressure scanner. The differential pressure transducer converts the pressure difference into the voltage.

A compensation air branch is connected to the negative input of the differential pressure transducer. This branch consists of pressure source, pressure control and gauge. It allows to regulate the compensation pressure in the range from 0 to $40 \mathrm{kPa}$. The air branch allows a precise control of a static pressure for the differential pressure transducer and therefore the balancing and adjusting of the correct pressure to the pulse point. This compensation pressure is equal to the addition of contact pressure of the probe to the artery and inside pressure of the fluid in the liquid branch. 
There are two independent tanks. One is fluid with measurement probe connected to the positive input, the other one is air, connected to the negative input of the differential pressure transmitter. This system of two independent tanks increases the sensitivity of the measuring process. The differential pressure transducer and its sensitivity determinate the measurement results enormously. For our device we used model BHV 5355 manufactured by BHV Sensors Prague. The differential pressure transducer converted the pressure differences to electrical voltage. The output voltage signal from the pressure transducer ranges from $-10 \mathrm{~V}$ to $+10 \mathrm{~V}$ depending on the pressure differences. This signal is transmitted to the measure card, which is directly connected to the PCMCIA port of the notebook computer. This method allows applying arbitrary static pressure to the pulse point, and consequently to the to artery.

The computer program was created in LabVIEW system. The program takes off the signal from PCMCIA measurement card with sampling frequency of $500 \mathrm{~Hz}$. The measuring program continuously displays the measured signal of a pulse wave on the screen. After recording has started, it puts a 30-seconds section of the pulse wave run into the memory and saves it as a file under a designated name. Then, again, it displays a received signal and it is ready for the next recording. The system also includes an evaluation program. The evaluation program opens a saved file by the name, displays the whole recorded pulse wave sequence and evaluates significant parameters.

The sensitivity of the differential pressure transducer is $20 \mathrm{~Pa}$ per $1 \mathrm{~V}$. The diameter of the palpation spot is a very important parameter, because it influences the sensitivity of the measurement. We have chosen the diameter of $9 \mathrm{~mm}$ for our purpose. Another important parameter is the diameter of the connecting hose, which should be as small as possible, so that the artery volume changes push out the minimum amount of the fluid.

The essential part of the device is the part for solving the membrane position on the probe in relation to the location on the artery. This is provided by a stabilization system. It consists of a holder and a probe-carrier, which is flexibly connected to the holder and allows variability of probe positioning towards the artery.

\section{Subjects}

We measured 108 healthy subjects, 78 females and 30 males all students from Palacky University Olomouc. They had no history of cardiovascular or other serious diseases and were on no medication. The age of individuals was $21.35 \pm 1.28$ years (mean \pm standard deviation SD) range 20.03-26.07 according IBP. The body height was $170.7 \pm 7.7 \mathrm{~cm}$ range $158.2-189.8$ measured by anthropometer from vertex to ink-lines. The weight of subjects was $61.71 \pm 9.91 \mathrm{~kg}$ range 45.62-94.28 measured by precision personal weight-machine. The medium subcutaneous fat amount of was $16.4 \pm 5.3 \%$, range 6.6-29.2 \% measured by Omron. From the height and weight we calculated body mass index BMI. The BMI was $21.10 \pm 2.45$ range 17.84-26.14.

We classified the pulse-wave parameters partly for the whole group and we concentrated mostly on physical body predisposition, because the measurement probe was on the surface. We divided the subjects into categories according to gender (males/females), subcutaneous fat (five groups: $0-10 \%, 10-15 \%, 15-20 \%, 20-25 \%$, more than $25 \%$ ) and BMI (four categories: underweight <18.5; normal weight 18.5-24.9; overweight 25.0-29.9; obesity 30 or greater).

\section{Analysis}

We described the mail pulse wave parameters according to Fig. 2. The time "A" is crest time, e.g. time to maximum systole peak, "T" is time of one pulse, e.g. between two diastoles, "T $1 / 3$ " is the latitude of systolic peak in $1 / 3$ of height from the top. By "a" we understand the length of perpendicular from the deflection point of linear increasing direction, " $b$ " is the length of perpendicular from catacrotic part, "c" is the amplitude of systolic peak and " $\mathrm{d}$ " is the amplitude of dicrotic wave peak. All

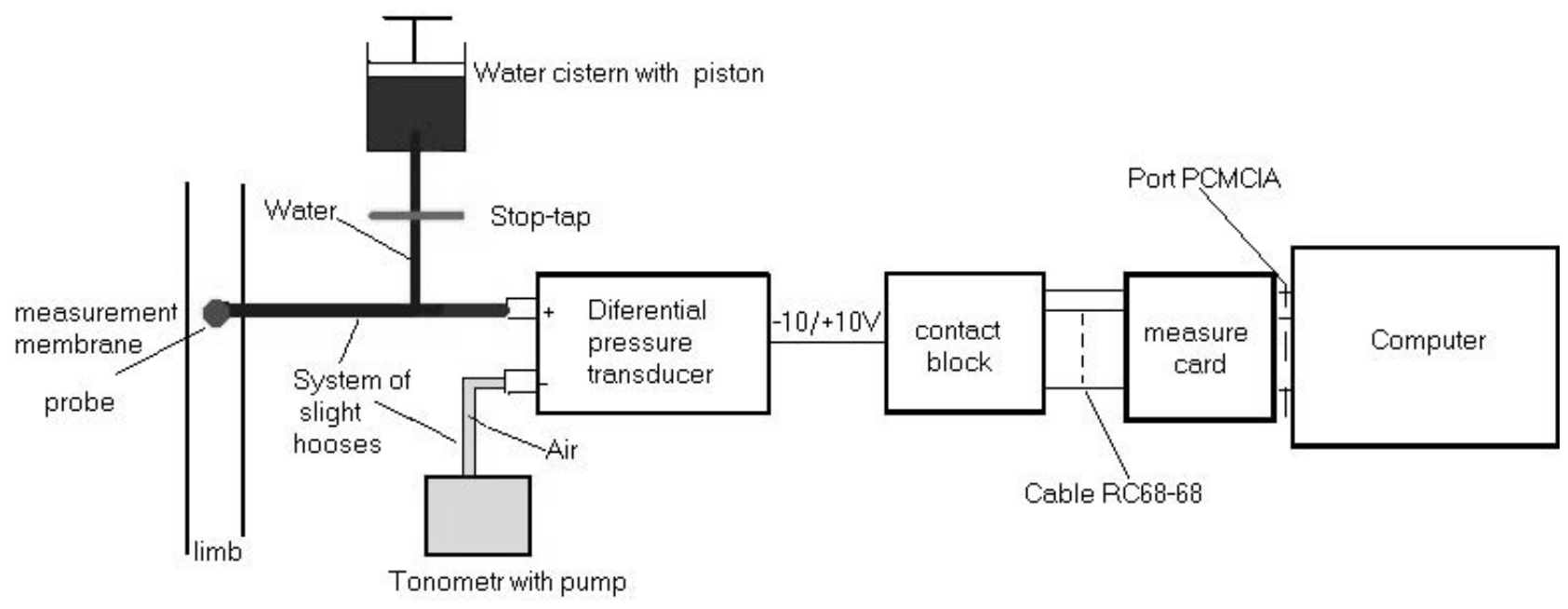

Fig. 1. General chart of device for measurement 
of these parameters depend on physiological conditions, and are used only in proportion relation. Relative crest time is ratio $\mathrm{A} / \mathrm{T}$, elasticity index is ratio $\mathrm{a} / \mathrm{b}$, dicrotic wave attenuation is ratio $\mathrm{d} / \mathrm{c}$, dicrotic wave time is $\mathrm{T} 1 / \mathrm{T}$ and interwave distance is $(\mathrm{T} 1 / 3) / \mathrm{T}$ (according to $\left.{ }^{5}\right)$.

We measured the volume pulse wave of 108 volunteers for 2 periods. Each subject laid in a quiet room in supine position for 5 minutes before the pulse wave and blood pressure recordings were measured. We used the left radial artery for the measurement. The measurement probe was placed on the artery palpation spot and positioned carefully until the signal was strong enough. After that the computer kept recording the signal for 30 seconds. In the pulse wave run, there were also some low-frequency waves in the blood pressure. We respected these waves in pulse wave run and we used a mean of all pulse waves under one respiratory wave as a valid value for each subject ${ }^{6,7}$.

Statistical analysis was done using the Statistica 5.5 software.

\section{RESULTS}

The group of 108 subject was divided according to the to gender, subcutaneous fat and BMI as shown in Table $1-3$. The values in the tables are given as mean \pm SD and are rounded to three decimal points. They were obtained by measurement program and statistically processed in required categories.

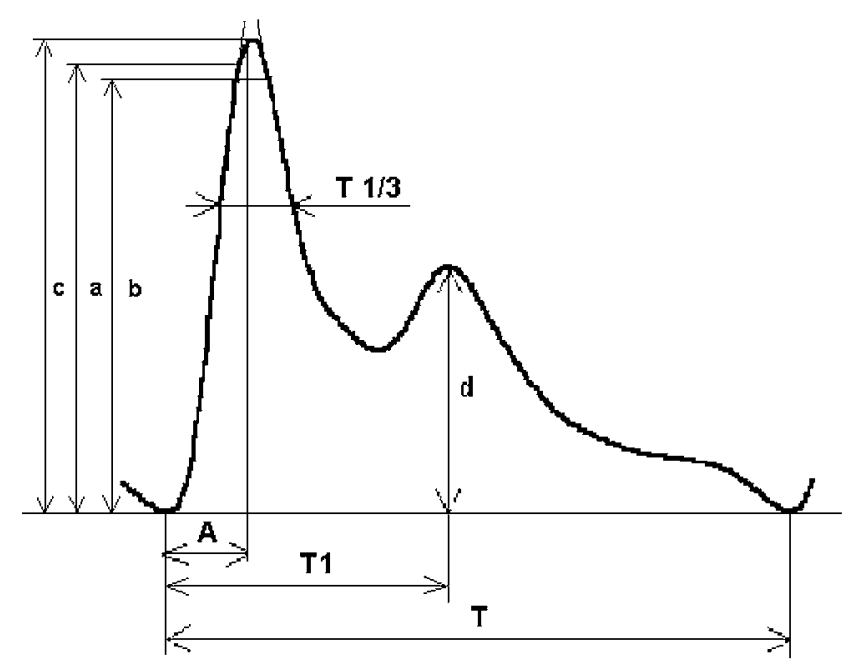

Fig. 2. Description of pulse wave

There were no significant differences between the observed categories using the two samples t-test in tested parameters at the significance level of $5 \%$. The variability coefficient during the whole measurement was $6.2 \%$ for relative crest time, $2.5 \%$ for elasticity index, $8.1 \%$ for dicrotic wave attenuation, $8.4 \%$ for dicrotic wave time and $6.2 \%$ for interwave distance. These variability coefficients are also interesting because of the evaluation of the pulse waves. It seems that the times-derived parameters have a better stability than the amplitude-derived ones.

Table 1. Dependence of pulse wave parameters on gender.

\begin{tabular}{|c|c|c|c|c|c|}
\hline $\begin{array}{c}\text { Category } \\
\text { (number) }\end{array}$ & $\begin{array}{c}\text { Relative crest } \\
\text { time }\end{array}$ & Elasticity index & $\begin{array}{c}\text { Dicrotic wave } \\
\text { attenuation }\end{array}$ & $\begin{array}{c}\text { Dicrotic wave } \\
\text { time }\end{array}$ & Interwave distance \\
\hline Males (30) & $0.129 \pm 0.020$ & $1.074 \pm 0.058$ & $0.521 \pm 0.085$ & $0.359 \pm 0.081$ & $0.118 \pm 0.019$ \\
\hline Females (78) & $0.127 \pm 0.036$ & $1.066 \pm 0.032$ & $0.542 \pm 0.115$ & $0.342 \pm 0.089$ & $0.124 \pm 0.038$ \\
\hline
\end{tabular}

Table 2. Dependence of pulse wave parameters on subcutaneous fat.

\begin{tabular}{|c|c|c|c|c|c|}
\hline $\begin{array}{c}\text { Category } \\
\text { (number) }\end{array}$ & $\begin{array}{c}\text { Relative crest } \\
\text { time }\end{array}$ & Elasticity index & $\begin{array}{c}\text { Dicrotic wave } \\
\text { attenuation }\end{array}$ & $\begin{array}{c}\text { Dicrotic wave } \\
\text { time }\end{array}$ & Interwave distance \\
\hline $0-10 \%(15)$ & $0.121 \pm 0.015$ & $1.075 \pm 0.029$ & $0.575 \pm 0.061$ & $0.343 \pm 0.087$ & $0.115 \pm 0.025$ \\
\hline $10-15 \%(30)$ & $0.137 \pm 0.034$ & $1.059 \pm 0.028$ & $0.553 \pm 0.109$ & $0.342 \pm 0.099$ & $0.135 \pm 0.049$ \\
\hline $15-20 \%(39)$ & $0.127 \pm 0.040$ & $1.075 \pm 0.055$ & $0.568 \pm 0.069$ & $0.355 \pm 0.091$ & $0.122 \pm 0.038$ \\
\hline $20-25 \%(15)$ & $0.120 \pm 0.019$ & $1.072 \pm 0.031$ & $0.569 \pm 0.114$ & $0.354 \pm 0.166$ & $0.130 \pm 0.020$ \\
\hline$>25 \%(9)$ & $0.126 \pm 0.011$ & $1.059 \pm 0.001$ & $0.580 \pm 0.015$ & $0.320 \pm 0.012$ & $0.126 \pm 0.008$ \\
\hline
\end{tabular}


Table 3. Dependence of pulse wave parameters on BMI.

\begin{tabular}{|c|c|c|c|c|c|}
\hline $\begin{array}{c}\text { Category } \\
\text { (number) }\end{array}$ & $\begin{array}{c}\text { Relative crest } \\
\text { time }\end{array}$ & Elasticity index & $\begin{array}{c}\text { Dicrotic wave } \\
\text { attenuation }\end{array}$ & $\begin{array}{c}\text { Dicrotic wave } \\
\text { time }\end{array}$ & Interwave distance \\
\hline$<18.5(12)$ & $0.128 \pm 0.007$ & $1.069 \pm 0.023$ & $0.545 \pm 0.031$ & $0.332 \pm 0.007$ & $0.124 \pm 0.051$ \\
\hline $18.5-24.9(84)$ & $0.128 \pm 0.035$ & $1.065 \pm 0.033$ & $0.537 \pm 0.154$ & $0.344 \pm 0.105$ & $0.130 \pm 0.044$ \\
\hline $25.0-29.9(12)$ & $0.134 \pm 0.015$ & $1.067 \pm 0.050$ & $0.511 \pm 0.118$ & $0.358 \pm 0.0522$ & $0.127 \pm 0.009$ \\
\hline
\end{tabular}

Table 4. General pulse wave parameters.

\begin{tabular}{|c|c|c|c|c|c|}
\hline $\begin{array}{c}\text { Category } \\
\text { (number) }\end{array}$ & $\begin{array}{c}\text { Relative crest } \\
\text { time }\end{array}$ & Elasticity index & $\begin{array}{c}\text { Dicrotic wave } \\
\text { attenuation }\end{array}$ & $\begin{array}{c}\text { Dicrotic wave } \\
\text { time }\end{array}$ & Interwave distance \\
\hline All (108) & $0.128 \pm 0.032$ & $1.068 \pm 0.042$ & $0.537 \pm 0.108$ & $0.346 \pm 0.088$ & $0.123 \pm 0.033$ \\
\hline
\end{tabular}

\section{DISCUSSION}

Our device represents a non-invasive, easy and movable technique for detection the pulse wave that allows assessment of arterial elasticity. The aim of the study was to confirm the reproducibility of pulse wave measurement by the new developed device on the different subjects. Comparing the values of all categories at significance level $5 \%$ we did not obtain any significant differences. This method is more sensitive for the measurement of the volume pulse wave shape than any other one, because of the great signal to noise rate at the output of differential pressure transducer. The study showed that the method gives reproducibility results and can be used for further classification of pathological curves. The comparison with the sensitivity of photoplethysmography, shows that our method is more sensitive for pulse wave measurement and it also enables detection of low frequencies of cardiac rhythms. Using of photoplethysmography is also limited to distal body part and it is not a suitable method for measurement on large arteries. Our method can be used even for carotid external artery.

The result shows that our method is reproducible for determining the volume pulse wave of surface arteries. As arteries lost their elasticity, the velocity of pulse wave and the amplitude of the reflected wave increased. This caused the changes in the pulse waveform, especially in the diastolic, dicrotic part. Increase of the amplitude of dicrotic wave is determinated by the parameter "dicrotic wave attenuation". Increase of the velocity is determinated by the parameter "dicrotic wave time". These two parameters provide useful information about arterial elasticity.

\section{REFERENCES}

1. Kamper AM, Anton JM, Gerard JB. (2001) Forearm Blood Flow Measurement Using Computerized R-wave Triggered Strain-gauge Venous Occlusion Plethysmography: Unilateral vs. Bilateral easurements. Clin Physiol 21, 524-527.

2. Hrazdira I. (2002) Quantitative Aspect of Doppler Vascular Diagnostic. Physician and Technology 33, 19-23.

3. Jong-jin L, Min-suk J In: Development of a Radial Artery Pulse Wave Transducer for Diagnostic of Human Body Constitution, Proceedings of the $32^{\text {nd }}$ International Symposium on Robotics. 19-21 April 2001.

4. Korpas D, Hálek J. (2003) Device for Pulse Wave Measurement and Analysis. Physician and Technology 34, 163-170.

5. Oliva I, Roztocil K. Pulsová vlna v diagnostice ischémické choroby dolních končetin. Prague, Avicenum, 1982.

6. Frey B, Butt W. (1998) Pulse Oximetry for Assesment of Pulsus Paradoxus: A Clinical Study in Children. Intensive Care Med 24, 242-246.

7. O'Rourke FM, Pauca A, Xiong-Jing J. (2001) Pulse Wave Analysis. J Clin Pharmacol 51, 507-522. 